Further experiments are in progress to examine in the early stages the growth of radium in actinium, initially freed from radio-actinium and all its products. If actinium changes directly into radium, the initial growth of the radium should be much smaller than that to be obtained three months later, when the products are in approximate equilibrium.

The results of my experiments are thus substantially in agreement with those of Dr. Boltwood. There is no doubt that the immediate parent of radium is present in actinium separated from pitchblende, but certain points remain to be settled before it is definitely proved that radium is the direct lineal descendant of actinium. Since the proof of this relationship between actinium and radium involves many important theoretical consequences, I think it is advisable to await the results of further experiment in this direction before basing far-reaching conclusions upon it.

McGill University, Montreal, January 3

\section{Helium and Argon in Common Rocks.}

THE quantity of radium found in granites and kindred rocks (Proc. Roy. Soc., A, vol. 1xxvii., p. 472), about $10^{-11}$ grams per c.c., suggested that the associated helium might be present in sufficient quantity for spectroscopic detection. This has proved to be the case. Thus 250 grams of Matopo granite yielded 3 c.c. of nitrogen on heating. This nitrogen, on sparking down, gave a residue of about $1 /$ Iooth part of its own volume. The residue was introduced into a vacuum tube, and showed the spectra of argon and helium quite brilliantly, and in about equal intensity. Similar results were obtained with syenite rocks from Mt. Sorrel in Leicestershire, and from Norway.

It seems more than probable that these observations afford an explanation of the nature of the gases evolved by mineral springs. The invariable presence of a notable quantity of helium in such gases has always been considered remarkable. It would seem that it may be sufficiently explained by the action of hot water in disintegrating common rocks and liberating the gases contained.

It is my intention to examine a large selection of common rocks and minerals, and particularly with the view of determining whether helium in them is always associated with radium, or whether its presence can ever be attributed to radio-activity of ordinary materials.

Sunnyside, Cambridge, January I3.

R. J. Strutt.

Ionisation and Absorption and Anomalous Dispersion.

Dr. Stark (NAture, vol. Ixxiii., pp. $78,389,533$ ) has given a theory, based on his canal-ray experiments, according to which spectrum series are due to positive ions. It occurred to me that its applicability to thermal emission might be tested by experiments on the ionisation accompanying the anomalous dispersion in sodium vapour. Accordingly, together with Mr. Needham, I made some preliminary experiments, using a slight modification of Prof. Wood's well-known apparatus " Physical Optics," p. 340), of which the results seem to be of sufficient interest to deserve publication.

We used a steel tube, $40 \mathrm{~cm}$. long, with an insulated iron wire stretched inside and along it about $\mathrm{I} \mathrm{cm}$. from the sodium surface. The poles of a battery were connected to the wire and tube through a liquid resistance and galvanometer ( $\mathrm{r}$ division $=\mathrm{ro}^{-8}$ ampere about); the tube was placed between the collimator and grating of a spectroscope, and the image of a horizontal fine wire stretched across the slit was observed in the first spectrum with a micrometer eye-piece. The separation, due to anomalous dispersion, of the two halves of the image on opposite sides of the absorption band was assumed to be a sufficient measure of the anomalous dispersion.

Curves constructed from observations of anomalous dispersion and current show that every variation of the ionisation, due to some irregularity of pressure and temperature, is accompanied by a corresponding variation in the anomalous dispersion.

The simplest explanation of the parallelism between the NO. I 942 , VOL. 75] curves is that the $\mathrm{D}$ lines of sodium are due to positive ions rather than to neutral atoms, in accordance with Stark's theory.

Physical Laboratory, University College of Wales,

Aberystwyth, December 20, 1906.

\section{THE MILLAIS BRITISH MAMMALS. ${ }^{1}$}

$W^{\text {ITH }}$ the appearance of this volume we have the pleasure of congratulating the author on the completion of a very heavy task. As we have had occasion to remark in our notices of the two earlier volumes, from the point of view of pictorial illustration the work is in the main all that can be desired, and there is little doubt that in this respect it will long remain absolutely without a rival. Our very heartiest congratulations may accordingly be tendered to Mr. Millais and his fellow artists on the result of their endeavours to illustrate in an adequate and exhaustive manner the living and recently exterminated mammals of the British Isles. In giving as the

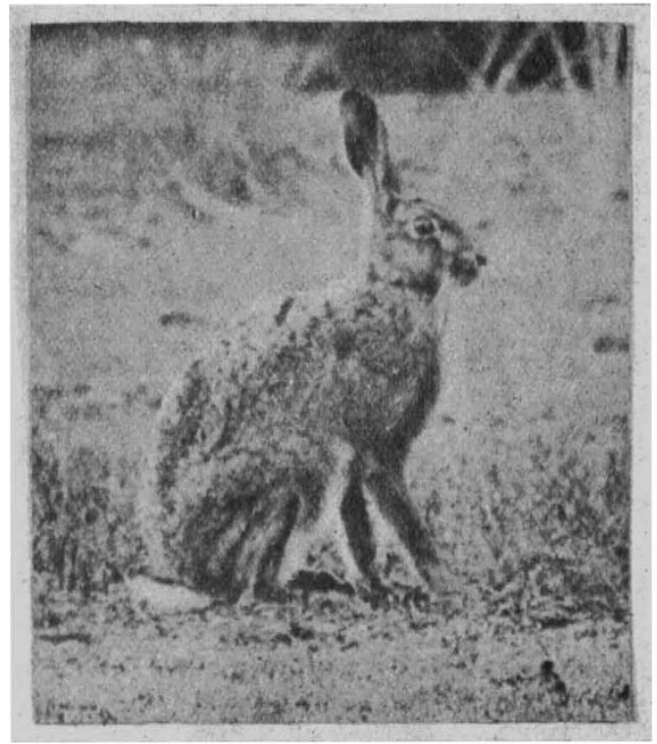

Fig. 1.-The Hare. From "The Mammals of Great Britain and Ireland."

frontispiece of the present volume a picture of a southern right-whale attacked by a party of grampuses, or killers, it may possibly be objected that the author has introduced a scene which cannot now be witnessed in British waters. Since, however, the past as well as the present state of the fauna of our islands enters into the purview of the work, there may be justification for such an illustration; and even if this be not the case, the privileges of artistic license may be pleaded as sufficient excuse. Had space been available, we should have had much pleasure in reproducing one of the full-page illustrations which form by far the most striking feature of the work. Failing this, we have to be content in presenting to our readers (by the courtesy of the publishers) three of the smaller illustrations as examples of the pictorial merit of the work.

The groups included in the present volume comprise the hares and rabbit; the ungulates, of which (if weexclude the white park-cattle, which are obviously not wild animals) the red deer, the fallow deer, and

1 "The Mammals of Great Britain and Ireland." By J. G. Millais. Vol. iii. Pp. xii +384 ; illustrated. (London: Longmans, Green and Co. 1906.) Price 61. 6s. net. 